fisheries is lamentably deficient, and that without further knowledge any legislation or attemp:s to improve our fisheries by better modes of fishing, or by protection or culture, must be dangerous, and, indee 1 , unreasonable."

Further, your Committee feel that in order to make any progress the work must be undertaken in a systematic manner ; the investigations must not be carried on by fit and starts, but continuously from month to month and from year to year, until all the facts have been collected and all the experiments made that are likely to throw any light on the difficult problems.

It having been alleged that the food fishes were disappearing from the eastern coasts of the United States, the Central Government in I87 I appointed a commissioner of fish and fisheries to inquire into the matter. The commissioner, instead of contenting himself with collecting evidence from people who knew little or nothing about the subject, proceeded to make careful and elaborate investigations. As the result of these inquiries the United States fisheries have been greatly improved, to the benefit of both the general public and the fishermen, and our knowledge of fish has been materially increased.

In the same way, and about the same time, a German Commission set to work, and although their results are not so striking, they are extremely interesting, a fourth section of their report, only published the other day, containing a careful description, with an outline drawing, of all the fish found in the Baltic.

The example set by America, Germany, and other Continental States we must follow. We have as a nation at last made a liberal acknowledgment of our ignorance, and at the conferences of the International $F$ isheries Exhibition expresied regret.

It is satisfactory that, while we are taking steps to increase our knowledge, we shall at one and the same time be improving our inshore fisheries. The measures necessary, e.g. for enabling us to discover for the first time when herring fry become maties, and when maties reach the stage of full herrings, are exactly the measures required for the artificial cultivation of the herring. From experience gained during the autumn we are now able to hatch immense numbers of herring; each herring produces from 30,000 to 50,000 eggs, but so small are they that 20,000 one layer thick can be placed on a square foot of glass, and from 1000 herrings it would be possible to obtain about $30,000,000$ fry, and this in from ten to fifteen days. It is well known that where there is an abundance of herring there is also an abundance of cod and other food fish, hence the annual introduction of some millions of young herring into our territorial waters might serve to attract numerous large food fishes to our shores. And what is true of the herring holds for many other useful fishes, and some of them, such as the sole and turbot, which are less migratory than the herring, might be manipulated in much the same way as trout and salmon, if we only knew more of their habits.

In order to be able to carry on the work of investigation, the importance of which is now universally recognised, the Committee recommend that an application be made for sufficient funds to enable the Board to establish a marine station, and further that a steam vessel take the place of the Vigilant at present at the service of the Board.

The Vigilant is in every respect inadequate for the ordinary work of the Board, and if there is added to that work the acquiring of new knowledge as to the habits of our food fishes, the nature of their food, their time and place of spawning, and the way in which these may be influenced by the various modes of fishing, a steam vessel will be absolutely necessary.

The Committee have much pleasure in stating that they are deeply indebted to Lieut. Prickett, in command of H.M.S. Jackal, for the ready assistance rendered by him and his officers, and for their unfdiling courtesy and kindness during the expedition.

'They bave also to state that it was a source of great satisfaction to them to find that the commander of the Vigilant was not only greatly interested in the work of the Corrmittee, but that, having a strong instinct for scientific work, he will be able to render mucb assistance in any further investigations that may be un dertaken.

To Mr. Romanes, F.R.S., the Committee are greatly indebted for many valuable suggestions, and they are also indebted for the use of the Marine Laboratory instituted some years ago by Mr. Romanes and Prof. Ewart. Without this laboratory much of the work which will form the substance of the forthcoming Report could not have been undertaken.

J. Cossar Ewar't, Convener

J. R. GIBSON-MAITTAND

A. FORBES IRVINF

J. MAX'TONE GRAHAX

Edinburgh, November 5

\section{THE ORIGIN OF CORAL-REEYS}

$\mathrm{SO}$ much additional information has in recent year been obtained regarding the physical and biological conditions of the sea that such a problem as that presented by the coral-islands of mid-ocean may well be reconsidered. Several able naturalists have lately called attention to this problem, and have insisted that the generally received solution of it is not satisfactory. Among geologists there may not unreasonably be a good deal of unwillingness to admit that this contention can be wellfounded. They have long been accustomed to regard Darwin's theory of coral-formation with justifiable pride as a masterpiece of exhaustive observation and brilliant generalisation. It has played an important part in their speculations regarding the larger movements of the earth's crust, and they have been so deeply impressed with its simplicity, and the grandeur of the conclusions to which it leads, that they will naturally and rightly refuse to surrender any portion of it save under the strongest compulsion of evidence. Some, incleed, may be inclined even to resent, almost with the warmth inspired by a personal injury, any attempt to slow that it can no longer claim the general applicability which has been regarded as one of the strongest arguments in its favour. But the example of Darwin's own candour and overmastering love of truth remains to assure us that no one would have welcomed fresh discoveries more heartily than he, even should they lead to the setting aside of some of his own work. I propose to give here somewhat in detail the more important data accumulated in recent years on this subject, and to state the conclusions to which a careful consideration of the evidence seems to me inevitably to lead.

Before the memorable voyage of the Beagle, the generally received opinion regarding the origin of the circular coral-reefs or atolls of mid-ocean was that they had grown up on the rims of submerged volcanic craters. The enormous size of some of the atolls-thirty miles in diameter-might have been thought a sufficiently formidable objection to this explanation. But it did not appear insuperable even to so cautious a philosopher as Lyell, who only noticed it to refer his readers to the great dimensions reached by truncated volcanic cones, which he thought might retain their forms more casily under a deep sea than on land. ${ }^{1}$

An earlier and better theory, as Darwin admitted, had been started by Chamisso, who supposed that the circular form of an atoll was due to the fact that, as the more massive kinds of coral thrive most vigorously in the play of the surf, they naturally keep to the outside of the reef, and raise that portion to the surfice 1 "Principles of Geology," 4th edit. (1835), vol. iii p. 310. 
first. But when Darwin's own views were publisbed, first in abstract before the Geological Society in 1837, and subsequently more fully in his separate volume on the Structure and Distribution of Coral-reefs in 1842 , they were soon generally accepted, and were regarded not only as affording a satisfactory explanation of the whole phenomena, but as comprising one of the most impressive generalisations with which geology, fertile in such achievements, had yet astonished the world.

The theory proposed by Darwin, now so familiar, connected all the types of reef together as stages of one long process, every step in which could be illustrated by actual examples. At the one end stood the fringing-reefs, some of which might only lately have been started upon a recently upraised sea-bottom. Out of this stage, by continuous or intermittent subsidence, came barrier-reefs. Then as depression went on and the islands encircled by the barrier-reefs disappeared, their sites were taken by atolls. Lastly, where the rate of subsidence was too rapid for the upward growth of the corals, an atoll might become a submerged bank. Not only was this explanation self-consistent, but it harmonised well with the conclusion, derived from totally different evidence, that there may have been widespread and long-continued subsidence over the ocean basins. It was moreover supported by the independent testimony of competent observers, who, with at least equal opportunities of studying the subject, bad espoused Darwin's views. Of these witnesses the most important was undoubtedly Prof. Dana, who accompanied the Wilkes Exploring Expedition of I838-42. Another powerful ally was found in Mr. Couthouy, who had studied coral-growth in the Pacific and in the West Indian seas. ${ }^{2}$ But even without the concurrent testimony of eye-witnesses the theory proposed by Darwin fitted so admirably into the geological theory of the day that it came itself to be used as one of the most cogent proofs of vast oceanic depression. And such is still the position which it bolds.

By a gradually widening circle of observation, however, a series of facts has been established, which were either not known or only partially known to Darwin. It should be borne in mind that, compared with more recent explorers, he did not enjoy a large opportunity of investi. gating coral-reefs. So far as can be judged from his published works, he appears to have examined only one atoll-the Keeling reef; and one barrier reef-that of

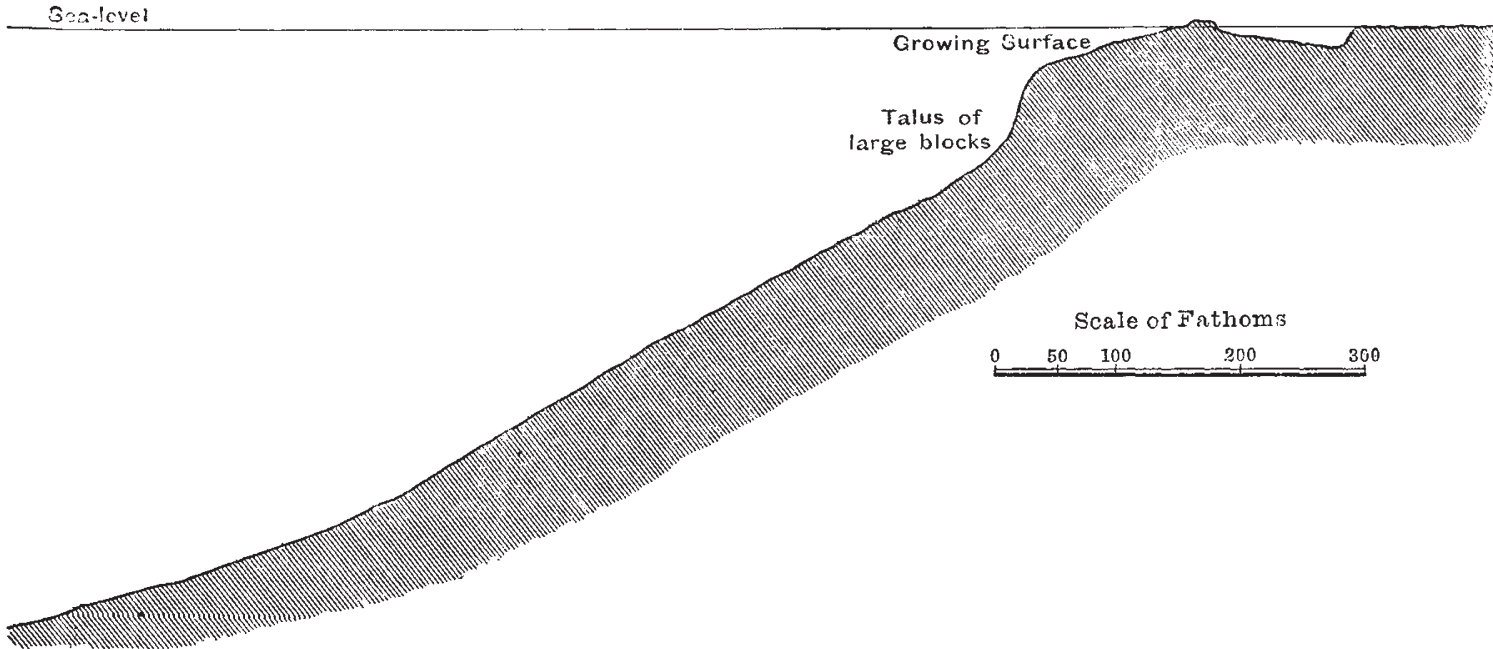

Frs. x-Section of the Barrier Reef, Tahiti, on a true sc lle, vertical and horizont al. By Mr. Murray and Lieut. Swire, R. N., of the Challenger Expedition.

Tahiti. The Admiralty charts, the work of previous voyagers, and unpublished information communicated to him, enabled him to extend his generalisation over the whole of the rest of the coral-regions which he had not personally explored. The deep-sea expeditions of recent years have now brought so much new light to bear on the whole question that we are in a much better position to discuss it than he was, nearly half a century ago. Of a tew of the more important investigations a brief résumé may here be given, and their bearing upon Darwin's theory of coral-reefs will then be discussed.

As far back as the year $185 \mathrm{I}$ the late L. Agassiz stated that, in his opinion, the theory of subsidence could not be applied in explanation of the Florida reefs; that on the contrary the southern end of Florida is built up on successive concentric barrier-reefs which have been gradually connected and cemented into continuous dry land by the accumulation of mud-flats between them, and that this process is still going on and must eventually convert the present keys and reefs from Cape Florida to the Tortugas into similar land.

In I 863 Prof. Carl Semper published the results of his

'Bull. Mhus. Comp. Zool., vol. i. See also J Le Conte, Silliman's 7oitmal, xxiit. (1857), p. 46 , and E. B. Hunt, op. cit. xxxv. (I 863), p. $3^{88 .}$ researches among the Pelew Islands. He found himself unable, by the theory of subsidence, to account for the phenomena there presented, and threw doubts on the general applicability of that theory. He pointed out that while the southern islands, probably once atolls, consist of coral-rock, upraised to from 400 to 500 feet above the sea, and are flanked by living coast-reefs, true living atolls exist at the northern end of the group. He contended that there is absolutely no evidence of subsidence, that the association of all the different kinds of reefs within so circumscribed an area seems entirely to disprove the notion of subsidence, and that, at least in this group of islands, Darwin's theory cannot be applied. In some suggestive observations on their probable origin, he remarks that the reefs depend mainly for their form upon the nature of the bottom on which they begin. Atolls are formed on submarine banks. A species of Porites takes root in little colonies varying from the size of the fist to masses six or eight feet in diameter. In time the central portions of these growing colonies die, while the outer

4 The narrative containing Prof. Dana's observations on coral-reefs was published among the Reports of the Expedition. In $187^{2}$ he published a volume on "Coral and Coral-Reefs," where he again gave the weight of his authority to the theory of subsidence.

2 Boston Journ. Nat. Hist., iv. $\left(1843^{-44}\right)$, p. 337 . 
parts flourish and gradually build up a ring of coral. This ring, which may be circular or elongated in form, is sometimes continuous, but more commonly is traversed by one or more channels. The interior portions are scoured out and deepened by the tidal currents. Or if the form of the bottom and other conditions be suitable, a great many individual masses of coral gradually grow into a more or less continuous reef, through which the strong ebb and flow of the tides serve to keep open some channels. Thus fringing-reefs, through the scour of the sea, become barrier-reefs, which retreat from the adjacent coast in proportion to the gentleness of the slope on which they are built. On a steeply shelving sea-bottom the reefs must obviously remain fringing-reefs.

Dr. Semper admitted that possibly many atolls and barrier-reefs were formed during subsidence, and even that the downward movement may in many cases have furnisbed the conditions for starting them into existence. The solution of the problem ought in each case, he thought, to be determined by actual detailed observation. But that the alternate currents of the tides are the main agents in the building of coral-reefs could be proved, he maintained, by many cases which, on the theory of subsidence, must be regarded as exceptional of inexplicable, such as the occurrence of true atolls in the midis of areas of elevation. ${ }^{1}$

In the second edition of his "Coral Islands," published in 1874 , Darwin briefly referred to these observations. He thought it not improbable that the Pelew Islands originally subsided, were afterwards upraised, and again subsided, but admitted that the proximity of fringing-reefs was opposed to his views. He suggested that if the submarine slope were steep reefs which began as fringingreefs would continue to be of that form, even during subsidence. There is, however, no admission that any valid objection had been made to his theory, or that true atolls and barrier-reefs might be formed in many places without subsidence.

In 1868 Prof. Semper reiterated his dissent from the prevailing theory of coral-reefs. ${ }^{2}$ Next year he reprinted his original paper (which seemed to him to have remained unknown to most naturalists) in a general account of the Philippine Islands, wherein he appended some additional notes. $^{3}$ In one of these he refers to the observations of Pourtales and others on a submarine calcareous deposit which in some regions is slowly being upraised to serve as a foundation for coral-reefs. To the objection that if atolls and barrier-reefs could be formed during a period of elevation, they ought to be found not merely at, or only slightly above sea-level, he replies that they are not in fact confined to that limited zone, but that even if they were, this would not invalidate his conclusion that the reefs are due to a complex cooperation of coral-growth with the waves and currents of the sea, and not to the one cause-the subsidence of entire regions-invoked by Darwin.

In the following year another contribution to the antisubsidence literature was made by Dr. J. J. Rein, who, in an interesting me noir on the physical geography of Bermuda, offered some observations on the coral-reefs of those islands. ${ }^{4}$ He suggested that the Bermuda group inight originally have been a submarine mountain or bank on which colonies of deep-water corals took root, and where other organisms flourished in such abundance as gradually to raise the top of the submerged ground to the zone in which reef-building corals could flourish. $\mathrm{He}$ adduced no evidence in support of this suggestion further than that there is no proof in Bermuda of subsidence,

"Zeitsch. Wissensch. Zoologie 1863 , xiii. p. 558 . Reprinted in 1869 in "I)ie Philippinen und ihre Bewohner" with additional notes.

"Verhandl. Physik-nled. Gesellsch.'Wurzburg; Sitzungsber., February I, 2
1868 .
3 ic 3 "Die Philippinen und ihre Bewohner." Würzburg, r869, pp. ז0o. 109. A brief account of the coral-reefs of the Philippine Islands will be found at pp. $19-33$

Beracht. Senckcnlierg. Naturforsch Gesellsch., 1869-70, p. I57. which, however, as Darwin had so cogently shown, from the very fact of the movement being downward, is in most cases not to be looked for.

An important memoir, marking a totally new departure in coral-reef literature, appeared in 1880 containing an abstract of observations made by Mr. Murray during the great voyage of the Challenger. ${ }^{1}$ The chief features of this contribution may be thus briefly summarised :-With hardly an exception the oceanic islands are of volcanic origin, and it is therefore to be presumed that the submarine ridges and peaks, which rise to within various distances from the surface, are likewise due to the protrusion of volcanic materials. There is thus no actual evidence of the still unsubmerged portions of any extensive continent or mass of land such as Darwin's theory requires. Whether built up above the sea-level into islands, or brought up to varying heights below that level, the volcanic eminences of the ocean may conceivably be brought into the condition of platforms for reef-builders by two causes. In the first place the erosive force of waves and tidal scour must tend to reduce all prominent oceanic summits to the lower limit of breaker-action, and thereby to produce truncated cones or flattened domes and ridges on which coral-reefs, if not already established, might spring up. In the second place, submarine eminences may have been brought up to within the zone of the reef-builders by the deposit of organic detritus upon them. One of the most remarkable results of recent deep-sea exploration has been the accumulated evidence of the extraordinary profusion of pelagic life in the tropical surface waters. From experiments made during the cruise of the Challenger, Mr. Murray estimated that, if the organisms are as numerous down to a depth of 100 fathoms as they were found to be in the track of the townet, there must be more than sixteen tons of carbonate of lime in the form of calcareous shells in the uppermost hundred fathoms of every square mile of ocean. The shells and skeletons of these organisms fall in a constant rain to the bottom, where they supply some of the food needed by the fauna which there subsists upon the mud. By the accumulation partly of these superficial exuvia, partly of the remains of the creatures living at the bottom, an organic deposit is growing over the seafloor in the tropical regions wherein coral-reefs flourish. Owing probably to the greater solvent action of the increased proportion of carbonic acid in sea-water at great depths, or to the greater mass of water throu, $h$ which they must sink, the shells of the upper waters seem never to reach the bottom or at least soon disappcar from it, for they are seldom met with in deep dredgings. But in shallower portions of the ocean they abound. Consequently it may be legitimately inferred that the rate of growth of the calcareous organic deposit on the seabottom must be more rapid in the shallower waters. The tops of submarine peaks and banks, being constantly heightened from this cause, will in course of time be brought up to a depth at which sponges, hydroids, deepsea corals, annelids, alcyonarians, mollusks, polyzos, echinoderms, and other organisms can flourish abundantly. When this has taken place, the upward growth of the calcareous formation will be accelerated by the accumulation of the remains of this abundant fauna as it lives and dies on the bottom. At last the zone of reef-building corals will be reached, and thereafter a growth of coralrock will bring the sea-floor up to the level of low water. That coral-reefs undistinguishable from barrier-reefs and even atolls might be formed upon banks of sediment in a deep sea was admitted by Darwin. ${ }^{2}$ But the assumption of so many submerged banks as this explanation would require, seemed to him so improbable that he dismissed it from further consideration. He was not aware, however, of the enormous abundance of minute cal

\footnotetext{
I Proc. Roy. Soc. Edin. (1879-80), x. p. 505
} 
careous organisms in the surface waters and of the comparative rapidity with which these remains might be accumulated on the sea-bottom.

Reef-builders starting on a submarine bank, whether prepared for them by erosion, by subsidence, or by the upward growth of organic deposits, would form reefs that must necessarily tend to assume the atoll form. The central portions of the colony or clump of coral will gradually be placed at a disadvantage as compared with the peripheral parts of the mass in being further removed from the food-supply, and will consequently dwindle and die. In proportion as the reef approaches the sea-level these central parts are brought into increasingly uncongenial conditions, until at last an outer ring of vigorous, growing coral-reef encircles an inside lagoon overlying the central stunted and dead portions. The possibility of such a sequence of events was likewise recognised by Darwin. "If a bank, either of rock or of hardened sediment," he says, "lay a few fathoms submerged, the simple growth of the coral, without the aid of subsidence, would produce a structure scarcely to be distinguished from a true atoll." 1

As the atoll increases in size the lagoon becomes proportionately larger, partly from its waters being less supplied with pelagic food and therefore less favourable to the growth of the more massive kinds of coral, partly from the injurious effects of calcareous sediment upon coral-growth there, and partly also from the solvent action of the carbonic acid of the sea-water upon the dead coral. The solution of dead calcareous organisms by sea-water is undoubtedly one of the most interesting facts brought to light by the naturalists of the Challenger Expedition.

Moreover, a connected chain of atolls might be formed on a long, submarine bank, and similar conditions of growth would then be displayed as in the case of a single atoll. The marginal atolls having a better supply of food would grow more vigorously than those towards the centre, and would tend to assume elongated forms, according to the shape of the bank beneath them. Many of them might coalesce, and might even ultimately give rise to one large atoll. Such a chain of atolls as that of the great Maldive group may be thus explained without the necessity for any disseverment by oceanic currents as Darwin supposed. On the other hand, the submerged coral-banks of the Lakadivh, Caroline, and Chagos archipelagos may be regarded as representing various stages in the growth of coral-reefs, some of them being still too deep for reef-builders, others with coral-reefs which have not yet quite grown up to the surface. But scattered among these banks are some of the most completely formed atolls. Mr. Murray contends that it is difficult to conceive how such banks can have been due to subsidence, when their situation with respect to each other and to the perfect atolls is considered. He reverses the order of growth as given by Darwin, who cited the great Chagos bank as probably an example of an atoll which had been carried down by a subsidence more rapid than the rate at which the corals could build upwards.

From a careful study of barrier-reefs Mr. Murray concludes that, in their case also, all the phenomena can be explained without having recourse to subsidence. He found from personal observation and a comparison of the Admiralty charts that most exaggerated notions prevail regarding the depth of water immediately outside the reef, which is usually supposed to be very great. After minutely exploring the barrier-reef of Tahiti, and sounding the water both inside and outside the reefs, he found that the slopes are just such as might be looked for on the susposition that the corals have grown up without any sinking of the bottom. The accompanying section (Fig. I), drawn to a true scale will show that there is nothing abnormal in the declivities. Beginning near the

op. cit. p. 134 . shore or wherever the bottom whether of rock or sediment comes within the range of the reef-builders, a barrier-reef grows vigorously along its outer face, while its inner parts, as in the case of an atoll and for the same reason, are enfeebled and die. The force of the breakers tears off huge masses, sometimes 20 or 30 feet long, from the face of the reef, especially where from the borings of mollusks, sponges, \&c., the coral-rock has been weakened. These blocks tumble down the seaward face of the reef, forming a remarkably steep talus. It is this precipitous part of the reef which has probably given rise to the notion that the water outside suddenly descends to a profound depth. The steep front of fallen blocks is succeeded by a declivity covered with coral sand, beyond which the bottom slopes away at an angle of no more than $6^{\circ}$, and is covered chiefly with volcanic detritus. Mr. Murray insists that any seaward extension of the reef must be on the summit of the talus of broken coral. The reef will gradually recede from the shore of the island or continent, and will leave behind here and there a remnant to form an island in the slowly broadening lagoon-channel.

The very general occurrence of proofs of elevation among the regions of barrier-reefs and atolls is in harmony with the volcanic origin of the ground on which these coral-formations have grown, but is, as Mr. Murray contends, most difficult of explanation on the theory of widespread subsidence. He affirms that all the chief features of coral-reefs and islands not only do not necessarily demand the hypothesis of subsidence, but may be satisfactorily accounted for, even in areas where the movement is an unward one, by the vigorous outward growth of the corals on the external faces of the reef in presence of abundant food, by their death, disintegration, and removal by the mechanical and chemical action of the sea in the inner parts, and by the influence of subzërial agencies and breaker-action in lowering the level of the upraised areas of coral-rock.

ARCH. GEIKIE

\section{(To be continued.)}

\section{NOTES}

IT will be seen from our Diary that the meeting of the Linnean Society on December 6 is to be exclusively devoted to the reading of a posthumous essay on Instinct by the Iate $\mathrm{Mr}$. Darwin. We are informed that this essay is full of important and hitherto unpublished matter with regard to the facts of animal instinct considered in the light of the theory of natural selection; and as the existence of the essay has only now been divulged, we doubt not that the next meeting of the Linnean Society will be of an unusually interesting character.

THE death is announced, at the age of seventy-six, of $\mathrm{Mr}$. John Eliot Howard, F.R.S., well known as a chemist and quinologist. He was the son of Mr. Iuke Howard, F.R.S., a well-known meteorologist in his day.

WE announced some time ago that the Finnish Senate had voted a sum of 37,002 marks to I'rof. Lemströn for the continuation of his experinents with the aurora boreali; at Sodankylä in the Finnish Lappmark during $1882-83$, of which he gave an account in NATURE (vol. xxvii. p. 389). The plan to be followed during the present winter at this station is to make observations three times in every twenty-four hours, with the exception only of the first and fifteenth of every $m$ onth, when they are made every five minutes throughout the twenty-four hours, and three days of the month when they will be effected every half minute during two hours. In order partly to obtain the necessary data for the control of the variation of the current from the atmosphere with the latitude, and partly to reduce the effect of probable influences, a branch station will be temporarily e tablished cluring the months of November, December, January, February, and part of March at the buildings of the Kultala gold 